\title{
The importance of early neurorehabilitation in the recovery of post-vaccination Guillain-Barre syndrome - a case report
}

\author{
Mihai Sava ${ }^{2,3}$, Maria-Gabriela Catană ${ }^{1}$, Corina Roman-Filip ${ }^{1,3}$
}

Corresponding author: Roman-Filip Corina - email: corinaromanf@yahoo.com,

\author{
${ }^{1}$ Emergency Clinical Hospital Sibiu, Department of Neurology \\ ${ }^{2}$ Emergency Clinical Hospital Sibiu, Intensive Care Unit \\ 3"Lucian Blaga" University, Sibiu, Romania
}

\begin{abstract}
Guillain-Barre syndrome (GBS) is the most common cause of acute flaccid paralysis worldwide, having an incidence of about 1/100,000 across several studies in a number of countries. We present the case of a 60 -year-old female patient, with known hypertension, admitted to our department for paresthesia and muscle weakness predominantly in the distal upper and lower limbs. Symptomatology had an acute onset after 14 days from influenza vaccine administration. Lumbar puncture revealed CSF glucose $(91 \mathrm{mg} / \mathrm{dl})$, CSF protein $(0.508 \mathrm{~g} / \mathrm{l})$ and no pleocytosis. Electromyography supported the presumptive diagnosis of polyradiculoneuritis. The patient underwent three sessions of double filtration and the final diagnosis was Guillain-Barre polyradiculoneuritis secondary to influenza vaccination. Approximately $80 \%$ of patients with polyradiculoneuritis recover completely within a few months to one year; however, $5-10 \%$ of these patients experience one or more recurrences. It should be emphasized that acute-phase rehabilitation must start immediately and include an individualized program of gentle strengthening, and manual resistive and progressive resistive exercises.
\end{abstract}

Key words: polyradiculoneuropathy, influenza vaccine, neurorehabilitation,

\section{Introduction}

Guillain-Barre syndrome (GBS) is the most common cause of acute flaccid paralysis worldwide, having an incidence of about $1 / 100,000$ across several studies in a number of countries $(1,2)$. GBS is thought to be an immune-mediated disease, in which antibodies in response to an antigenic stimulus, such as bacterial or viral infection, cross-react with nerve ending antigens (2). GBS became a major vaccine safety concern in 1976, when there was a threat of a swine-origin influenza pandemic and the United States government initiated a national vaccination program. After approximately 45 million people were vaccinated, an increased number of post-vaccination GBS cases were reported. The risk was found to be highest 2-3 weeks after vaccination. The attributable risk was estimated at 1 additional case of GBS for every 100,000 doses administered (3). In 2006, Juurlink et al. studied the association of GBS with influenza vaccines administered during 1992-2004 in Canada; using a self-controlled case series design, they found a small but significant increased risk of GBS in the 6 weeks following receipt of influenza vaccine (relative risk [RR] $1.45 ; 95 \%$ confidence interval [CI] 1.05-1.99) (4). In November 2009, prospective cohort analyses showed a small increased risk of GBS within 6 weeks of vaccination and an attributable risk of approximately 1 additional case of GBS per million persons vaccinated (5). Final analyses confirmed this small increased risk within 6 weeks of vaccination $(6,7)$.

\section{Case report}

We present the case of a 60-year-old female patient, with known hypertension, admitted to our department for paresthesia and muscle weakness predominantly in the distal upper and lower limbs. Symptomatology had an acute onset after 14 days from influenza vaccine administration. At admission, the patient was hemodynamically stable, with a blood pressure of $140 / 80 \mathrm{mmHg}$ and a heart rate of 80 beats/minute. She had no fever and no other abnormalities at the general examination. The neurological examination revealed: no clinical signs of meningeal irritation, no neck rigidity, wide-based gait, bilateral proximal muscle weakness in the lower limbs (4/5 MRC) accompanied by paresthesia in the same areas, globally abolished osteotendinous reflexes, and bilateral plantar flexion. A presumptive diagnosis of polyradiculoneuritis was established and differential diagnosis included myelitis, polyneuropathies, myasthenia gravis, Lyme disease, and even neuromyelitis optica (NMO) because in the earliest stages of the disease, the clinical presentation of 
NMO spectrum disorder (NMOSD) can overlap or mimic other inflammatory diseases of the CNS (8). All the above mentioned were excluded by electromyography, lumbar puncture and clinical exam (for example, the patient reported no sensory impairment or painful spasms or visual disturbances which are known to be associated with NMO in $32 \%$ of the cases) (8). Lumbar puncture was decided, which revealed CSF glucose $(91 \mathrm{mg} / \mathrm{dl})$ and CSF protein $(0.508 \mathrm{~g} / \mathrm{l})$ without pleocytosis. Other serology test results, including for hepatitis $\mathrm{C}$ virus (HCV), hepatitis A virus (HAV), human immunodeficiency virus (HIV), syphilis and Lyme disease, were negative. Under these circumstances, it was obvious that electromyography was necessary. Electromyography was performed on the same day in the Neurophysiology Department and highlighted: normal NCS on the cubital, radial, peroneal and sural nerves; markedly reduced distal motor response amplitude - 40\% left peroneal muscle block. A significant MUAP dispersion was observed. F-wave latency was at the upper limit, with significant dispersion (Figures 1,2). The tables below include all the tested nerves (Tables 1, 2, 3).

The patient's general condition gradually deteriorated: motor deficit worsened, the patient was unable to stand and walk, her spontaneous $\mathrm{O} 2$ saturation was $89 \%$, which required her transfer to the Intensive Care Unit in order to start plasmapheresis.

After administration of the first dose of albumin, the patient experienced arrhythmias, marked dyspnea, hypotension (blood pressure 50/30 $\mathrm{mmHg}$ ), bradycardia (heart rate 40 beats/min), symptomatology that partially remitted under cortisone therapy and adrenaline. The double plasma phase filtration procedure was initiated immediately. The patient underwent three sessions of double filtration, after which her clinical condition improved. EMG, lumbar puncture and clinical findings allowed reaching a final diagnosis: Guillain-Barre polyradiculoneuritis secondary to influenza vaccination.

Our patient started the rehabilitation program with a physiotherapist very early. This program included a complete range of motion and strengthening exercises necessary for mobility. Strengthening began in a gravity eliminated plane to allow repetitions without excessive fatigue. During this time, mobilization of the patient into sitting or out of bed to a chair was performed in order to promote pulmonary hygiene, circulation, and increase tolerance to upright postures. The rehabilitation program started with a Hughes scale score of 4 , and after 21 days, a score of 2 was reached. The patient was recommended to continue rehabilitation in order to increase independence and safety with activities of daily living. Early initiation of a rehabilitation program can assist in preventing secondary complications, while later, therapists can assist with strengthening and increasing functional independence. In our opinion, a multidisciplinary team approach allows achieving the best outcomes for the patient.

\section{Discussions}

Monitoring for GBS following influenza vaccination remains important; enough evidence can be obtained to better understand the complex relationships between influenza, influenza vaccines, and the risk of GBS. There is sufficient evidence supporting an increased risk of GBS during the 6 weeks following receipt of seasonal influenza vaccine (1). As opposed to infectious causes, elevated protein levels (100 $1000 \mathrm{mg} / \mathrm{dl}$ ) appear in the CSF without an accompanying increased cell count (pleocytosis), as happened in our case (2).

In our case, it would have been helpful to coadminister IV immunoglobulins with double filtration, but the patient developed multiple allergies and side effects during the plasmapheresis session, which is why this possibility was excluded.

Rehabilitation should focus on proper limb positioning, posture, and orthotics. GBS patients frequently require psychological support, given the extremely disabling and frightening aspects of the condition and its sequelae (9). There is an increasing trend to use ultrasound in the management of pain. Knowing that ultrasound is one of the electrotherapy procedures applied due to its analgesic effects, muscle relaxing properties and massage, this might be used in the rehabilitation of patients with motor deficits (10).

Approximately $80 \%$ of patients with polyradiculoneuritis recover completely within a few months to one year; however, $5-10 \%$ of these patients experience one or more recurrences.

The particularity of the presented case is that the pathology appeared after vaccine administration, which is rarely reported in the literature. 
Table 1.

MOTOR CV

\begin{tabular}{|c|c|c|c|c|c|c|c|c|c|c|}
\hline Test & $\begin{array}{l}\text { Stimulation } \\
\text { site }\end{array}$ & $\begin{array}{l}\text { Lat., } \\
\text { ms }\end{array}$ & $\begin{array}{l}\text { Ampl., } \\
\text { mV }\end{array}$ & $\begin{array}{l}\text { Dur., } \\
\text { ms }\end{array}$ & $\begin{array}{l}\begin{array}{l}\text { Area, } \\
m V \times m s\end{array} \\
m a\end{array}$ & $\begin{array}{l}\text { Stim., } \\
\text { mA }\end{array}$ & $\begin{array}{l}\text { Stim., } \\
\text { ms }\end{array}$ & $\begin{array}{l}\text { Dist., } \\
\text { mm }\end{array}$ & $\begin{array}{l}\text { Time, } \\
\text { ms }\end{array}$ & $\begin{array}{l}\text { Vel., } \\
\mathrm{m} / \mathrm{s}\end{array}$ \\
\hline \multicolumn{11}{|c|}{ right, Abductor digiti minimi, Ulnaris, C8 T1 } \\
\hline \multirow[t]{2}{*}{12} & wrist & 2,64 & 11,2 & 6,64 & 36,5 & 18 & 0,2 & 70 & & \\
\hline & elbow & 6,24 & 10,6 & 7,12 & 35,7 & 42 & 0,2 & 210 & 3,6 & 58,3 \\
\hline \multicolumn{11}{|c|}{ right, Abductor pollicis brevis, Medianus, C8 T1 } \\
\hline \multirow[t]{2}{*}{10} & wrist & 5,6 & 8,09 & 9,08 & 35,3 & 30 & 0,2 & 80 & & \\
\hline & elbow & 9,32 & 7,42 & 9,72 & 32,9 & 30 & 0,2 & 220 & 3,72 & 59,1 \\
\hline \multicolumn{11}{|c|}{ right, Abductor hallucis, Tibialis, I4 L5 S1 } \\
\hline \multirow[t]{2}{*}{2} & sole of the foot & 3,8 & 7,4 & 19,5 & 50,8 & 36 & 0,2 & 70 & & \\
\hline & popliteal fossa & 13,0 & 4,94 & 20,1 & 38,3 & 100 & 1 & 420 & 9,16 & 45,9 \\
\hline \multicolumn{11}{|c|}{ right, Extensor digitorum brevis, Peroneus, I4 L5 S1 } \\
\hline \multirow[t]{2}{*}{1} & sole of the foot & 6,99 & 3,16 & 18,5 & 22,1 & 48 & 0,2 & 70 & & \\
\hline & head of fibula & 15,7 & 1,98 & 16,9 & 14,2 & 56 & 0,2 & 340 & 8,68 & 39,2 \\
\hline \multicolumn{11}{|c|}{ left, Extensor digitorum brevis, Peroneus, I4 L5 S1 } \\
\hline \multirow[t]{2}{*}{5} & sole of the foot & 3,28 & 9,74 & 7,32 & 37,7 & 29 & 0,2 & 70 & & \\
\hline & head of fibula & 10,0 & 5,7 & 7,76 & 23,6 & 100 & 0,2 & 300 & 6,76 & 44,4 \\
\hline
\end{tabular}

Table 2.

SENSORY CV

\begin{tabular}{|c|c|c|c|c|c|c|c|c|c|c|}
\hline Test & \begin{tabular}{|l} 
Stimulation \\
(recording) sites
\end{tabular} & $\begin{array}{l}\text { Lat., } \\
\text { ms }\end{array}$ & $\begin{array}{l}\text { Ampl., } \\
\mu \mathrm{V}\end{array}$ & $\begin{array}{l}\text { Dur., } \\
\text { ms }\end{array}$ & $\begin{array}{l}\text { Area, } \\
n V \times s\end{array}$ & $\begin{array}{l}\text { Stim., } \\
\text { mA }\end{array}$ & $\begin{array}{l}\text { Stim., } \\
\text { ms }\end{array}$ & $\begin{array}{l}\text { Dist., } \\
\mathrm{mm}\end{array}$ & \begin{tabular}{|l} 
Time, \\
ms
\end{tabular} & $\begin{array}{l}\text { Vel., } \\
\mathrm{m} / \mathrm{s}\end{array}$ \\
\hline \multicolumn{11}{|c|}{ right, Ramus superficialis $\mathrm{n}$. radialis, C5 C6 } \\
\hline 9 & 1 & 1,48 & 12,0 & 0,96 & 6,1 & 17 & 0,1 & 80 & 1,48 & 54,1 \\
\hline \multicolumn{11}{|c|}{ right, $\mathrm{n}$. Medianus } \\
\hline 8 & wrist & 4,88 & 2,8 & 1,32 & 2,0 & 17 & 0,1 & 140 & 4,88 & 28,7 \\
\hline \multicolumn{11}{|c|}{ right, n. Ulnaris } \\
\hline 7 & wrist & 2,08 & 5,2 & 2,36 & 6,7 & 25 & 0,1 & 120 & 2,08 & 57,7 \\
\hline \multicolumn{11}{|c|}{ right, n.Peroneus superficialis, L4-S1 } \\
\hline 4 & Middle third of leg & 1,84 & 14,7 & 1,48 & 13,1 & 16 & 0,1 & 85 & 1,84 & 46,2 \\
\hline \multicolumn{11}{|c|}{ right, n.Suralis, S1-S2 } \\
\hline 6 & 1 & 2,56 & 7,4 & 1,32 & 5,0 & 17 & 0,1 & 115 & 2,56 & 44,9 \\
\hline
\end{tabular}

\section{Table 3.}

F-WAVE PARAMETERS

\begin{tabular}{|c|c|c|c|c|c|c|c|}
\hline Test & $\begin{array}{l}\text { Fmin } \\
\text { lat., ms }\end{array}$ & $\begin{array}{l}\mathrm{F} \text { ampl., } \\
\mu \mathrm{V}\end{array}$ & $\begin{array}{l}\text { M lat., } \\
\text { ms }\end{array}$ & \begin{tabular}{|l|} 
Fmin-M \\
lat., ms
\end{tabular} & $\begin{array}{l}\text { Fmean/M } \\
\text { ampl., \% }\end{array}$ & $\begin{array}{l}\text { Max Vprox, } \\
\text { m/s }\end{array}$ & $\begin{array}{l}\text { V prox. } \\
\text { diff., m/s }\end{array}$ \\
\hline \multicolumn{8}{|c|}{ right, Abductor digiti minimi, Ulnaris, C8 T1 } \\
\hline 13 & 26,2 & 661 & 2,6 & 23,6 & 4,0 & & \\
\hline \multicolumn{8}{|c|}{ right, Abductor pollicis brevis, Medianus, C8 T1 } \\
\hline 11 & 28,0 & 726 & 5,56 & 22,5 & 6,2 & & \\
\hline \multicolumn{8}{|c|}{ right, Abductor hallucis, Tibialis, I4 L5 S1 } \\
\hline 3 & 52,7 & 357 & 3,8 & 48,9 & 3,1 & & \\
\hline
\end{tabular}



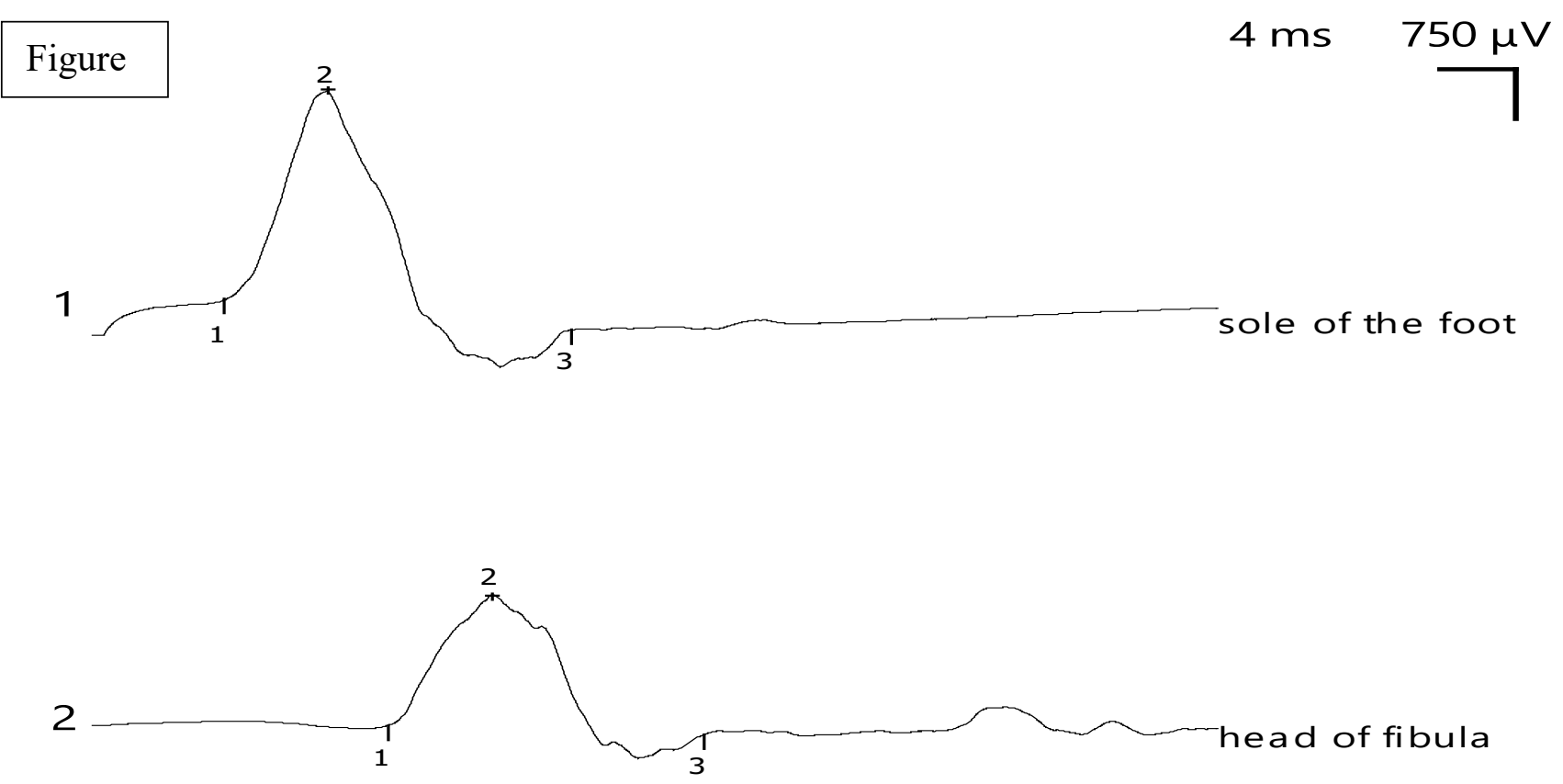

Fig. 1. Right, Extensor digitorum brevis, Peroneus, L4 L5 S1

M-wave amplitude with stimulation at the distal site $3.16 \mathrm{mV}$. Residual latency $5.2 \mathrm{~ms}$. Velocity in the "sole of the foot - head of fibula" segment $39.2 \mathrm{~m} / \mathrm{s}$.

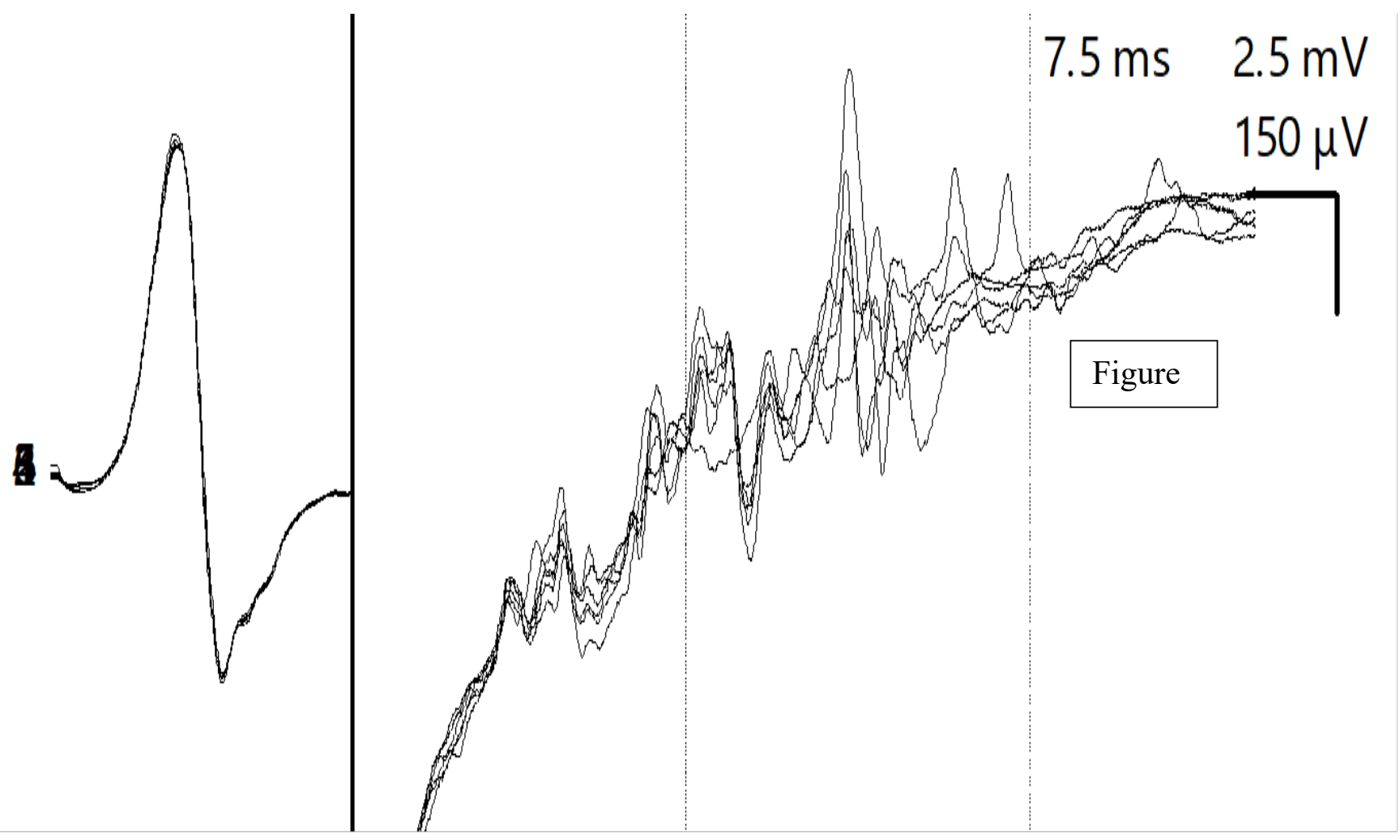

Fig. 2. F-WAVE Right, Abductor hallucis, Tibialis, L4 L5 S1. Min F-wave latency $52.7 \mathrm{~ms}$, max $58.7 \mathrm{~ms}$, mean $53.9 \mathrm{~ms}$, difference $6.0 \mathrm{~ms}$. Mean F-wave amplitude is $357 \mu \mathrm{V}$. F/M amplitude ratio: max 3.8\%, mean 3.1\%. No repetitive waves. No blocks, no gigantic waves. Peripheral latency $27.8 \mathrm{~ms}$. 


\section{Conclusions}

In our case, it was very important to recognize the neurological pathology. Neurological rehabilitation should be initiated immediately after immunological treatment has been completed (plasmapheresis).

Acute-phase rehabilitation for Guillain-Barre polyradiculoneuritis should include an individualized program of gentle strengthening, and manual resistive and progressive resistive exercises (11). Physiotherapists assist to correct functional movement, avoiding harmful compensations that might have a negative effect in the long run. There is also some evidence supporting the role of physiotherapy in helping GBS patients to regain strength, endurance, as well as to prevent contractures and bedsores (12).

All in all, we would like to highlight that the benefits of influenza vaccination outweigh the minor risks of post-vaccination GB syndrome.

\section{Conflict of interest}

There is no conflict of interest for any of the authors regarding this paper.

\section{Informed consent}

An informed consent was obtained from the patient included in this study.

\section{References}

1. Vellozzi C, Iqbal S, Broder K. Guillain-Barré Syndrome, Influenza, and Influenza Vaccination: The Epidemiologic Evidence. Clin Infect Dis. 2014 Apr;58(8):1149-55.

2. EL-Said A. M. Emergent management of Guillain-Barré syndrome, Journal of Anesthesiology. 2014; 07:88-95.

3. J. B. Winer. An Update in Guillain-Barré Syndrome. Autoimmune Dis. 2014; 2014: 793024.

4. Juurlink D, Stukel T, Kwong J, et al. GuillainBarre syndrome after influenza vaccination in adults - a population-based study. Arch Int Med 2006; 166:2217-21.
5. Centers for Disease Control and Prevention. Preliminary results: surveillance for GuillainBarre syndrome after receipt of influenza A (H1N1) 2009 monovalent vaccine-United States, 2009-2010. MMWR Morb Mortal Wkly Rep 2010; 59:657-61.

6. Tokars J, Lewis P, DeStefano F, et al. The risk of Guillain-Barre syndrome associated with influenza A (H1N1) 2009 monovalent vaccine and 2009-2010 seasonal influenza vaccines: results from self-controlled analyses. Pharmacoepidemiol Drug Saf 2012; 21:546-52.

7. Wise M, Viray M, Sejvar JJ, et al. Guillain-Barre syndrome during the 2009-2010 H1N1 influenza vaccination campaign: population-based surveillance among 45 million Americans. Am J Epidemiol. 2012;175:1110-9.

8. Roman-Filip C, Ungureanu A, CernuşcăMiţariu M. Painful tonic spasms and brainstem involvement in a patient with neuromyelitis optica spectrum disorder. Polish Journal of Neurology and Neurosurgery. 2016;50(1):55-8.

9. Pithadia A, Kakadia N. Guillain-Barré syndrome (GBS). Pharmacol Rep 2010; 62:220-232.

10. Silisteanu S, Antonescu E, Szakacs J, Totan M, Roman Filip C, Serb B, Cernusca Mitariu M, Grigore N, Cernusca Mitariu S. Study on Changes in Some Physiological Parameters Under the Action of Therapeutic Ultrasound, Chemistry Magazine. 2017;68(6):1404-1407

11. Hughes RA, Wijdicks EF, Benson E, et al. Supportive care for patients with Guillain-Barré syndrome. Arch Neurol 2005; 62:1194-1198.

12. Davidson I, Wilson C, Walton T, Brissenden S. Physiotherapy and Guillain-Barré syndrome: results of a national survey. Physiotherapy. 2009; 95:157-163. 